\title{
La comunidad jurídica en Kant. La necesidad de la virtud para la viabilidad del proyecto republicano 1
}

\section{(The juridical community in Kant. The necessity of virtue for the republican project viability)}

\author{
Luis Alegre Zahonero y Carlos Fernández Liria \\ Universidad Complutense de Madrid \\ luis.alegrezahonero@gmail.com / ferliria@gmail.com
}

Recibido: 23 de abril de 2010

Aceptado: 25 de noviembre de 2010

\section{Resumen}

En el planteamiento de Kant, el estado civil de derecho debe regirse exclusivamente por los mandatos de una legislación jurídica. La facultad de coaccionar (indisociable del derecho) no puede estar mezclada con nada ético. Sin embargo, en el presente artículo se trata de defender que, desde el propio planteamiento de Kant, la política en general (y, por lo tanto, también el desarrollo legislativo ordinario de cualquier sistema de derecho) resultan imposibles si no se supone cierta virtud cívica.

Palabras Clave: Naturaleza humana, comunidad jurídica, comunidad ética, estado civil, virtud, Kant.

\begin{abstract}
According to Kant, civil state must be ruled only by juridical legislation. Coercion (necessarily joint to legal system) cannot be related to ethical questions. Nevertheless, the present article tries to demonstrate that, according to Kant, politics in general (including any legal ordinary development) would be impossible if it was not supposed any civic virtue.
\end{abstract}

Keywords: Human nature, juridical community, ethical community, civil state, virtue, Kant.

$\overline{1}$ Este trabajo ha sido realizado en el marco de los Proyectos de Investigación "Naturaleza humana y comunidad I" y "II" (HUM2006-04909 y FFI2009-12402), financiados por el MICINN. 


\section{La comunidad jurídica en Kant como asunto específico de los seres racionales pero finitos}

¿Cómo construir un mundo en el que nadie vea amenazada su libertad y su integridad por la acción de los demás? ¿cómo lograr que cada uno pueda perseguir su propia felicidad como considere más oportuno sin que resulte incompatible con que los demás puedan también hacerlo en las mismas condiciones? ¿cómo garantizar a todos la máxima libertad y la integridad de su propia persona y de aquello que tengan derecho a reclamar como suyo?

Estas cuestiones, que en definitiva encierran todo el problema del Derecho ${ }^{2}$, son relevantes sólo para esos sujetos en los que la Razón no es la única candidata a determinar la voluntad. En un mundo de ángeles, estas preguntas serían del todo innecesarias e incluso absurdas. Atendiendo al planteamiento de Kant, no sería posible que ningún acto particular respondiese a máximas que no pudieran valer a su vez como leyes universales ${ }^{3}$. En este sentido, no harían falta leyes coactivas para garantizar que el arbitrio de cada uno puede conciliarse con el arbitrio del otro según una ley universal de la libertad.

Una "voluntad santa" no necesitaría del derecho para nada pero, dada la naturaleza humana, no está en absoluto garantizado que la voluntad se determine siempre, necesariamente, por consideraciones de validez general. En efecto, entre seres racionales pero finitos, puede perfectamente ocurrir que, por decirlo así, lo que "pida el cuerpo" sea perseguir la propia felicidad al margen de cualquier otra consideración, es decir, incluso a costa de las condiciones para la felicidad ajena. El problema, claro está, no es tanto que el cuerpo, digamos, "lo pida" sino que la voluntad esté siempre tentada de aceptarlo (al menos entre nosotros los humanos).

En la medida en que se está dotado de razón, sin duda es posible comprender que cada uno somos nada más que "uno cualquiera" (sin más prerrogativas ni privilegios que cualquier otro) y, por lo tanto, que la búsqueda de nuestra felicidad debe resultar compatible con el derecho de todos los demás a perseguir la suya en las mismas condiciones. Pero, dada la naturaleza humana, no basta comprender esto para convertirlo ya, automáticamente, en fundamento de determinación de la voluntad. En efecto, las cuestiones relativas a nuestra propia felicidad tienden a afectarnos de un modo particularmente intenso y, por lo tanto, tienden a acaparar cierto protagonismo en todo lo relativo a la determinación de la voluntad. Resulta siempre muy tentador considerar las condiciones de nuestra propia felicidad, si se quiere decir así, más particulares que las de cualquier otro. En este sentido, se abre de

\footnotetext{
2 Debe recordarse que, en la Metafisica de las costumbres, Kant define el derecho como el "conjunto de condiciones bajo las cuales el arbitrio de uno puede conciliarse con el arbitrio del otro según una ley universal de la libertad", Kant (1797), p. 230.

3 En efecto, una voluntad santa es "incapaz de máxima alguna que no pueda ser al mismo tiempo ley objetiva". Kant, (1788), p. 32.
} 
hecho la posibilidad de actuar según máximas que no podrían de ningún modo valer como leyes.

En estas condiciones, ¿cómo imponer la compatibilidad entre la libertad de cada uno y la de todos los demás? ¿cómo garantizar la vigencia de una voluntad universalmente legisladora regulando la coexistencia entre los hombres?

Debe advertirse que el Derecho (aunque se trate de un asunto que sólo es relevante respecto a sujetos con varios candidatos a determinar su voluntad) no debe inmiscuirse en valoraciones de orden moral. En efecto, lo que persigue el Derecho es garantizar la apertura de un espacio libre de obstáculos para el ejercicio de la libertad y, por lo tanto, remite exclusivamente a los elementos exteriores de la acción. En este sentido, la legalidad o no de las acciones debe ser considerada al margen de su moralidad 4 . Lo mismo da que el respeto a la libertad y la integridad ajenas esté motivado por un sentimiento interno de deber o que esté motivado por la amenaza con sanciones. Desde el punto de vista del derecho, basta con que, en efecto, se respete externamenten la integridad y la libertad ajenas 5 .

Así pues, ¿cómo imponer legislativamente la apertura de ese espacio para la libertad de todos?, ¿cómo garantizar por medio de leyes de derecho públicas que ese espacio se halla libre de obstáculos incompatibles con la forma de ley? En términos kantianos, la única respuesta posible remite a un sistema de leyes de coacción que, atendiendo a lo que establece el principio de todo derecho externo, restrinja la libertad de cada uno a las condiciones bajo las cuales pueda coexistir con la libertad de cualquier otro según una ley general. A este sistema de leyes coactivas que regulan la actividad externa de los individuos para ajustarla a este principio lo llama Kant "estado civil de derecho" o "comunidad jurídica" (para diferenciarlo de un estado civil ético o comunidad ética) 6 .

\footnotetext{
4 "A la mera concordancia o discrepancia de una acción con la ley, sin tener en cuenta los móviles de la misma, se le llama la legalidad (conformidad con la ley), pero a aquélla en la que la idea del deber según la ley es a la vez el móvil de la acción, se le llama la moralidad (eticidad) de la misma". Kant (1797), p. 219

5 Algunos autores como Habermas o Dowrkin han intentado encontrar en Kant un planteamiento que subordinaría el derecho a la moral. Contra esta interpretación, Kervégan sostiene la radical autonomía del derecho respecto a la normatividad ética. En efecto, según sostiene Kervégan, "es legítimo afirmar que la filosofía práctica de Kant, tomada en su evolución, tiende hacia una mayor autonomía del derecho frente a la ética”. Kervégan (2009), p.17. A este respecto, sostiene que incluso el derecho cosmopolita resulta en Kant independiente de la normatividad ética.

6 Recordemos que, para Kant, "un estado civil de derecho (político) es la relación de los hombres entre sí en cuanto están comunitariamente bajo leyes de derecho públicas (que son en su totalidad leyes de coacción). Un estado civil ético es aquel en el que los hombres están unidos bajo leyes no coactiva, esto es: bajo meras leyes de virtud." Kant (1793), p. 95.
} 


\section{Necesidad de desconectar las exigencias del derecho de las exigencias de la virtud}

No obstante, resulta siempre muy tentador (y extremadamente peligroso) intentar resolver este problema recurriendo a la virtud más que al derecho. En efecto, un pueblo de ángeles no tendría por qué estar sometido a la imposición de coacciones y, además, la virtud accedería a rincones donde la coacción no puede alcanzar. En este sentido, toda comunidad política puede (incluso debe) desear la vigencia de leyes de virtud que faciliten el cumplimiento del deber. Si, además garantías coactivas, se lograra implantar una comunidad ética (no sólo jurídica) regida por leyes de virtud, la vida de cualquier comunidad política sería mucho más fluida y menos litigiosa ${ }^{7}$.

La conquista que esto supondría desde el punto de vista de los intereses de la Razón sería tan espectacular que, en ausencia de Crítica, el propio proyecto racionalista podría quedar cegado por la ambición de instaurar legislativamente una comunidad ética. Pero, "¡ay del legislador”, nos advierte Kant, "que quisiera llevar a efecto mediante coacción una constitución erigida sobre fines éticos! Porque con ello no sólo haría justamente lo contrario de la constitución ética, sino que además minaría y haría insegura la constitución política" (Kant 1973: 96). En efecto, la pretensión de regular coactivamente las intenciones y los móviles que determinan subjetivamente el arbitrio no puede sino fracasar de un modo estrepitoso: por mucho que la coacción lo intente, no podrá nunca acceder más que a los elementos exteriores de la acción y, por contra, el intento de acceder al fundamento interno de determinación del arbitrio (espacio que, por principio, le está vedado al derecho) no puede sino terminar disolviendo todo el sistema de seguridad jurídica y garantías procesales que debe corresponder a un sistema de derecho.

A este respecto, han proporcionado ya suficiente escarmiento los proyectos políticos que, durante el siglo XX, han tratado de basarse en la forja de un "hombre nuevo" moralmente superior al mero miembro de una "comunidad jurídica" (vinculado objetivamente a las leyes comunes pero al que no se exige que demuestre un compromiso ético con las reglas generales); un "hombre nuevo" de una consistencia comunitaria tan implacable que no debía tener siquiera la posibilidad de movilizarse subjetivamente por motivos distintos a los del respeto por los fines comunes

\footnotetext{
${ }^{6}$ Recordemos que, para Kant, "un estado civil de derecho (político) es la relación de los hombres entre sí en cuanto están comunitariamente bajo leyes de derecho públicas (que son en su totalidad leyes de coacción). Un estado civil ético es aquel en el que los hombres están unidos bajo leyes no coactiva, esto es: bajo meras leyes de virtud." Kant (1793), p. 95.

7 Debe tenerse en cuenta que todo el edificio del derecho explotaría si, en vez de cumplirse las leyes de un modo espontáneo e implícito y explicitarse sólo (por medio de la policía y los jueces) en los momentos en los que fueran violadas, estuviesen siempre global y permanentemente explícitas (ya fuese con todo el mundo violando las leyes o ya fuese con todo el mundo calculando a cada instante si le conviene más cumplirlas o no).
} 
y las reglas generales. En este sentido, los conceptos de "autonomía", "libertades individuales" o "independencia civil" fueron en ocasiones etiquetados como "individualistas" y, en consecuencia, promotores del egoísmo (condenando como "individualismo pequeño burgués" lo que no era sino el concepto mismo de ciudadanía). El consiguiente e inevitable intento de pensar un "más allá" de la comunidad jurídica obligó por ejemplo a cierta tradición marxista ${ }^{8}$ a coquetear con toda suerte de holismos y comunitarismos que, en su ensalzamiento de los valores de la cooperación y lo colectivo, estaban necesariamente abocados a fundar una especie de nueva religión. Se anunciaba un "hombre nuevo" destinado a superar el egoísmo del individualismo burgués. Así, se abría la puerta a la recuperación de un comunitarismo asfixiante que, lejos de conducir a una nueva "tierra prometida" más allá de la mayoría de edad que la Ilustración había resumido en el concepto de ciudadanía, terminó (como no podía ser de otro modo) desembocando en el ya conocido más acá de la minoría de edad y el adoctrinamiento moral, algo parecido al infantilismo de la mentalidad puritana, rigorista y militante de las sectas religiosas. La historia dejó muy claro que más allá del Derecho sólo se encontraba el más acá de la tradición, la superstición y la religión (ajena a los límites de la razón).

Así pues, por mucho que la constitución de una comunidad ética pudiese resultar una aspiración inevitable de la Razón, es también imprescindible que ésta se mantenga dentro de sus límites y asuma su plena incapacidad para imponer coactivamente nada relativo a la consistencia ética de los ciudadanos. El derecho no puede pretender nunca ir "más allá" de considerar idéntico a efectos legales cumplir las leyes por miedo a las sanciones o por compromiso moral con el punto de vista general que corresponde al legislador. Lo relevante para el derecho no es la consistencia moral de los hombres sino la legalidad de sus acciones. Lo relevante para el derecho no es si los ciudadanos son movidos subjetivamente por la representación del interés general y la asunción como propia de una legislación que valga para todos. Lo relevante para el derecho es que los ciudadanos se comporten, así sea por coacción externa, como lo hubieran hecho en caso de haber decidido moralmente. El objetivo para el derecho es, sin más, que se atienda al mandato de las leyes, es decir, que se actúe de un modo conforme a las reglas que rigen para todos. El derecho debe ceñirse pues a garantizar que las acciones, en todos sus aspectos externos, responden a lo establecido desde el punto de vista de quien legisla con validez general. 9

\footnotetext{
${ }^{8}$ En el libro El orden de 'El capital'(que próximamente será publicado por la editorial Akal) tratamos de demostrar que esta deriva de cierta tradición marxista no es imputable al propio Marx, a quien sí cabe ubicar de un modo nítido en el interior de la tradición republicana e ilustrada que nunca ha estado dispuesta a dar esos saltos al vacío.

9 "Así como el derecho en general sólo tiene por objeto lo que es exterior en las acciones, el derecho estricto, es decir, aquel que no está mezclado con nada ético, es el que no exige sino fundamentos externos de determinación del arbitrio; porque entonces es puro y no está mezclado con prescripciones referidas a la virtud". Kant (1797), p. 232
} 


\section{Comunidad jurídica y pueblo de demonios}

El asunto de la comunidad jurídica remite a la organización de un estado según reglas de validez general acatadas por todos ya sea por compromiso ético o ya sea por imperativo legal. La cuestión no es en absoluto (más bien al contrario) cómo regir un pueblo de ángeles. El problema es simplemente cómo diseñar el sistema de reglas e instaurar los mecanismos de sanción suficientes para que, incluso los más reacios a actuar acatando un punto de vista válido para todos, se vean forzados a hacerlo. Dado el sistema de incentivos y sanciones adecuado, respetarán las reglas comunes incluso quienes más propensión tengan a hacer excepciones consigo mismos. Dada una eficacia suficiente en la administración de los premios y penalizaciones, incluso quienes no son en absoluto movidos subjetivamente por la representación de reglas generales ni del interés común, actuarán como si hubieran hecho propio el sentimiento de respeto por las reglas que valen para todos y como si hubieran actuado movidos por él. Es decir, dada la adecuada organización del Estado, incluso un pueblo de demonios (con tal que fueran inteligentes) actuará como si no existieses las tendencias egoístas. El planteamiento de Kant a este respecto es contundente: una buena organización del Estado, "lo que efectivamente está en manos de los hombres" (Kant, 1795: 366), puede orientar las tendencias egoístas de modo que queden neutralizadas en sus efectos externos. "El resultado para la razón es como si esas tendencias [egoístas] no existieran y el hombre está obligado a ser un buen ciudadano aunque no esté obligado a ser moralmente un hombre bueno. El problema del establecimiento del Estado tiene solución incluso para un pueblo de demonios (siempre que tengan entendimiento)" (Kant, 1795: 366). ${ }^{10}$

En efecto, dada esta correcta organización del Estado, no hace falta moralizar a la ciudadanía y fundar un pueblo de ángeles para que incluso los demonios se comporten (por efecto de la coacción externa) como si lo hicieran moralmente. Ahora bien ¿cabe imaginar a un pueblo de demonios trabajando por la construcción de un sistema que les obligue a comportarse de ese modo? Sin duda cabe imaginar un sistema de incentivos y penalizaciones que les haría comportarse como buenos ciudadanos (aunque estén lejos de ser hombres buenos) pero ¿se afanarán en diseñarlo y hacerlo entrar en vigor? A este respecto, tiene toda la razón A. Domènech cuando, a propósito de Kant, sostiene que "los demonios inteligentes quizá se comporten

10 En El concepto de lo civil, Felipe Martínez Marzoa recoge este planteamiento con una radicalidad a nuestro entender ya excesiva: "Es correcto decir que la situación óptima, en materia de derecho y poder civil, es aquella en la que se podría tranquilamente asumir que todos somos deshonestos en extremo, toda vez que la situación, el juego de fuerzas, es tal que está claro que saldríamos perdiendo si no actuásemos conforme a derecho, $\mathrm{y}$ en la que las personas en cada momento elegidas para ser gobernantes o legisladores o jueces pueden sin problema ser deshonestísimos individuos que, a la vista del juego de fuerzas, actúan conforme a derecho por la cuenta que les tiene. Por el contrario, confiar parte de la cuestión a que las personas sean buenas es una concesión al principio despótico, en el que, en efecto, las cosas van bien si el déspota es bueno.” Martínez Marzoa (2008), p. 79. 
como "buenos ciudadanos" bajo una tal constitución, una vez establecida, pero ciertamente no contribuirán un ápice a su advenimiento" (Domènech, 1989: 283).

No pocas revoluciones han fracasado, y siguen fracasando, porque quienes toman el poder del Estado deciden apropiarse de los privilegios en vez de suprimirlos. Incluso en los casos en los que el objetivo expreso es instaurar un verdadero estado civil republicano, es frecuente encontrarse de hecho con que el proyecto de transformación política queda suplantado por una sustitución de las élites que se benefician de la deficiente organización del Estado en términos republicanos. En este sentido, no es de extrañar que tradicionalmente se haya exigido al verdadero revolucionario una "consistencia moral" más allá de la que se requiere para ser simplemente un "buen ciudadano". En efecto, el momento de la transformación social requiere un compromiso con la justicia y con la equidad que va, por definición, más allá de lo que exigen coactivamente las leyes de derecho públicas de la organización política que debe quedar atrás. Ciertamente, no es imposible pensar un sistema de reglas que impidiesen del modo más radical todo tipo de corrupción o degeneración burocrática incluso en un pueblo de demonios. Pero no es probable que, si una muchedumbre de demonios toman el poder del Estado, vayan a instaurar ese sistema de reglas. Así pues, la instauración de un estado civil republicano por un pueblo de demonios requeriría ya siempre de antemano la existencia de un sistema de reglas coactivas orientado a ese fin.

Ahora bien, el problema que se plantea respecto a la posibilidad de instaurar un sistema de reglas que obligase a todos a ser buenos ciudadanos ( $\sin$ necesidad de exigir que fuesen personas buenas) no se plantea sólo respecto a la posibilidad de una transformación revolucionaria. Por el contrario, cualquier reforma legislativa ordinaria plantea también la necesidad de suponer ciertos elementos de virtud cívica como condición de posibilidad del proyecto republicano. No se trata en absoluto de reclamar al "ciudadano" ninguna consistencia moral tan implacable que le exigiera entregarse por completo a la causa de lo común (y disolverse en ella). Sin embargo, en absoluta ausencia de todo compromiso ético con los asuntos comunes, tampoco tenemos la figura de un "ciudadano" sino, en todo caso, la de un "comerciante". Sin un cierto compromiso más o menos extendido con los asuntos públicos (lo cual requiere, por decirlo así, cierto elemento de virtud republicana) sencillamente no es viable el proyecto de un estado civil. No sólo no es probable que pudiera ser instaurado sino que ni siquiera sería posible su reforma legal ordinaria para adaptarlo progresivamente a la idea de derecho. Todo estado civil presupone determinados elementos de civismo que corresponden necesariamente a la idea misma de ciudadano y, por lo tanto, no hay República viable sin cierto compromiso asentado con las cuestiones públicas. 


\section{El problema de la política: derecho, discusión pública y virtud cívica}

El problema planteado hasta aquí puede resumirse en tres pasos:

a) No hay derecho sin política. Como ya hemos comentado, una voluntad santa, ciertamente, no requeriría del derecho para nada. Sin embargo, esta posibilidad está vedada para nosotros los humanos. Los seres racionales pero finitos (en los que la Razón no es la única candidata a determinar la voluntad) no podemos prescindir de un sistema de normas que se impongan coactivamente sobre los elementos externos de la acción (y no, claro está, sobre las intenciones). Tal como hemos expuesto, se tratará de un sistema de Derecho en la medida en que las normas busquen simplemente establecer "el conjunto de condiciones bajo las cuales el arbitrio de uno puede conciliarse con el arbitrio del otro según una ley universal de la libertad" (Kant, 1797: 230). Ahora bien, esto que Kant establece como Principio Universal del Derecho no es todavía el derecho positivo. Por el contrario, para desarrollar cualquier cuerpo legislativo se requiere de un largo proceso de actividad que permita ir materializando ese principio general en leyes, normativas, estatutos, reglamentos, directrices y ordenanzas concretas. Y esta es, en efecto, una de las tareas principales de esa actividad política que Kant define como doctrina del Derecho en ejercicio (Kant 1795: 370). En efecto, esa peculiar puesta en ejercicio de los principios del Derecho que corresponde a la política (o, mejor dicho, que debería corresponder a la política si ésta fuese lo que verdaderamente le correspondería ser en el marco del proyecto de la Ilustración) no tiene tanto que ver con la tarea de determinar qué regla es aplicable a cada caso en particular (lo cual es más bien función de la administración de justicia) como con la tarea de organizar un ordenamiento positivo de un modo compatible con el Principio Universal del Derecho. Ciertamente, los tribunales deberán garantizar tanto que la realidad se ajuste a las reglas positivas como que las propias leyes sean compatibles con la norma fundamental que rija una determinada comunidad jurídica. Pero es impensable la idea misma de un ordenamiento jurídico sin suponer decisiones políticas. Para empezar, no hay puesta real del derecho en ejercicio sin la instauración de una Constitución y, sin duda, elaborar una Constitución no es una cuestión puramente técnica que dependa en exclusiva de la razón teórica. La Constitución de un cuerpo civil no es un producto que emana de los Departamentos de Derecho Constitucional sino de los órganos políticos a los que se asigna funciones legislativas constituyentes. Corresponde a cada comunidad jurídica decidir qué norma fundamental quiere darse. Sin duda es cierto que no cualquier conjunto de "Leyes Fundamentales" es propiamente una Constitución (pues, para serlo, no puede dejar de ajustarse en todos sus extremos al Principio Universal de Derecho). Pero también es cierto que este principio Universal no permite deducir una Constitución positiva particular sino que, por el contrario, se limita a proporcionarnos un patrón de medida con el que juzgar, por decirlo así, la constitucionalidad de cualquier norma fundamental (es decir, permi- 
te en todo caso diferenciar las verdaderas constituciones de los ordenamientos despóticos camuflados). Del mismo modo, cualquier desarrollo legislativo posterior, desde las leyes orgánicas hasta las ordenanzas y circulares, debe ser enjuiciado a la luz de ese Principio pero no puede ser deducido a partir de él11.

b) No hay política sin discusión pública. No hay ningún procedimiento por el que se pueda derivar de un modo automático todo lo relativo a la compatibilidad o no con el Principio Universal del Derecho de los usos, costumbres y tradiciones que rigen (u ordenan) una sociedad dada. Por el contrario, esto es algo que sólo se puede ir alcanzando a través de la discusión ciudadana mediante procedimientos institucionales diseñados para ese fin, siendo el principal de estos procedimientos, claro está, la discusión parlamentaria. Pero no cualquier cosa que se hable en un Parlamento merece ya propiamente el nombre de "discusión ciudadana". Para que esto se dé, es necesario que sus miembros comparezcan como ciudadanos libres, dispuestos a argumentar y contraargumentar; dispuestos a convencer y dejarse convencer por las razones ajenas; dispuestos a interpelar a cualquiera para que razone a la búsqueda del interés general y dispuestos a someterse ellos también al mismo principio. Esto exige, ante todo, la disposición a modificar los propios planteamientos en el transcurso de la deliberación como resultado de lo planteado en ella; exige, pues, la disposición a rechazar consideraciones propias si se demuestra que dependen de razones privadas y que no son asumibles como decisiones públicas; exige también cierta confianza en que las posiciones del interlocutor tampoco están totalmente petrificadas y que, por lo tanto, se discute con alguien que podría renunciar a sus puntos de vista originales si descubriese que se basan en razones privadas, quizá perfectamente legítimas, pero no aptas para reclamar el acuerdo público.

11 En este sentido, cabe matizar la afirmación anterior según la cual un pueblo de ángeles no necesitaría el derecho para nada. Ciertamente, tiene razón Wolfgan Kersting cuando sostiene que "la proverbial bondad de los ángeles sólo puede llevar a un orden espontáneo de la convivencia si hay leyes universalmente conocidas y suficientemente determinadas según las cuales pueden orientarse todos. Tampoco hay tales leyes para los ángeles en un estado de naturaleza, pues dado que para los ángeles y los hombres se trata de una y la misma razón, el derecho racional para el pueblo de los ángeles no es más favorable en la determinación de lo que es para la humanidad. Así que entre los ángeles también se producirán disputas jurídicas. Éstas no llevarán ciertamente a una justicia privada violenta, pero irritarán bastante al pueblo de los ángeles, de forma que pensarán un remedio y se unirán en una voluntad legislativa general. Los costes de imposición del derecho serán evidentemente minúsculos en esta comunidad de ángeles". Kersting (2009), p. 84. En efecto, ninguna voluntad santa regulará su comportamiento según máximas que no pudieran al mismo tiempo valer como leyes universales, pero esta piedra de toque no proporciona ya por sí sola una legislación concreta de validez universal. Por lo tanto, no podrán eludir cierta dedicación a la tarea de determinar qué sistema legislativo concreto adoptar entre todos (de entre los distintos sistemas posibles aptos para reclamar una posible validez general). De un modo gráfico (y casi trivial), cabe decir que un pueblo de ángeles podría quizá prescindir de un Código Penal, pero no, por ejemplo, de un código de la circulación que estableciese regulaciones concretas sobre si circula por la derecha o por la izquierda (ambas opciones igualmente aptas para reclamar su posible validez general pero entre las que hay que optar de un modo tajante y mutuamente excluyente si se quiere evitar un desastre). 
Todo lo contrario de la discusión, claro está, es ese mecanismo de negociación (que remite más bien a dinámicas mercantiles) en el que no cabe suponer que haya nada más allá de los intereses particulares. En este caso, las preferencias de cada cual se establecen estrictamente en privado y están determinadas de un modo inamovible con anterioridad al proceso de diálogo. A partir de aquí, se podrá intentar llegar a acuerdos, buscar las componendas o cerrar los tratos que resulten más ventajosos para los intereses particulares de cada uno, pero sería absurdo negociar recriminando a las posiciones enfrentadas no ser sostenibles como razón pública, ya que ni siquiera pretenden en ningún caso un estatuto tal. 12

c) No hay discusión pública sin virtud. Ahora bien, en ausencia absoluta de todo compromiso ético por parte de los ciudadanos, no cabe suponer nada distinto a intereses particulares blindados sobre los que se está dispuesto, en todo caso, a negociar. En este sentido, un pueblo de demonios puede dar lugar a la "armonía" de un Mercado, pero no a la racionalidad de un Parlamento. Un pueblo de demonios también puede estar obligado por leyes coactivas a comportarse como buenos ciudadanos, pero no pueden ser obligados a dejarse convencer de la conveniencia de adoptar leyes que les obligasen a ser todavía mejores.

La disposición a deliberar, a convencer y a ser convencido y la permeabilidad hacia los argumentos, es decir, la actitud necesaria para estar en condiciones de buscar el bien común en el espacio de la razón pública, requiere de un elemento de honestidad y de compromiso con los asuntos públicos que no puede ser impuesto en ningún caso coactivamente y que, por lo tanto, escapa al dominio del Derecho. Por el contrario, el Derecho mismo necesita presuponerlo como su condición de posibilidad. En efecto, sería casi un imposible lógico buscar procedimientos coactivos para obligar a los legisladores a dejarse convencer cuando en el foro de la razón pública (es decir, el Parlamento) se demostrase la "inferioridad" de sus argumentos, pues esto presupondría otro espacio diferente como sede de la razón pública con capacidad para juzgar, al margen del Parlamento mismo, sobre la validez de los diferentes argumentos (lo cual, claro está, no haría más que desplazar el problema al infinito hacia otra sede legislativa distinta sin que pudiese jamás resolverse).

A este respecto, la analogía con la razón teórica puede ser ilustrativa. La Verdad también exige ser perseguida (al menos entre nosotros los humanos) a través de la argumentación y la discusión, en este caso, en el seno de la Academia. Este proce-

12 Tiene sin duda razón Carl Schmitt cuando sostiene que "el parlamento sólo será "real" en tanto que la discusión pública sea tomada en serio y llevada a efecto. "Discusión" posee a este respecto un sentido especial y no significa simplemente negociar. (...) La discusión significa un intercambio de opiniones; está determinada por el objetivo de convencer al adversario, con argumentos racionales, de lo verdadero y lo correcto, o bien dejarse convencer por lo verdadero y lo correcto. (...) Por otra parte, las negociaciones, cuyo objetivo no es encontrar lo racionalmente verdadero, sino el cálculo de intereses y las oportunidades de obtener una ganancia haciendo valer los propios intereses según las posibilidades, van acompañadas, por supuesto, también de discursos y discusiones, pero no se trata de una discusión en el correcto sentido" Schmitt (1923), pp. 7-8. 
so, al igual que el desarrollo legislativo para ajustarlo a la idea de Derecho, nunca se puede dar por concluido de un modo definitivo: lo más lejos que podemos siempre llegar (en un proceso sin fin) es a corregir errores pasados por medio de construcciones teóricas nuevas. Ahora bien, este recorrido de la razón teórica resulta inviable si no se presupone cierta honestidad académica y cierta entrega y compromiso, por decirlo así, con la causa de la Verdad. Ciertamente, cualquier sistema coactivo que se arbitre para imponer por medio de reglas externas esa entrega y compromiso fracasará estrepitosamente $y$, con toda probabilidad, supondrá la ruina de la Academia. Pero una cosa es decir que la facultad de coaccionar (por ejemplo a través de agencias de evaluación de la calidad) no logrará nunca garantizar ese compromiso y otra distinta es sostener que es viable el proyecto de la Verdad en total ausencia de honradez científica.

En el caso de la política, la piedra de toque de la validez no será el juicio de la comunidad científica (a la que no se puede dejar de suponer en todo momento comprometida hasta cierto punto con la causa de la verdad) sino el escrutinio del espacio público (al que no se puede dejar de suponer hasta cierto punto comprometido con la causa de la justicia). En efecto, un espacio público completamente corrompido (desde un punto de vista moral) no podría propiamente cumplir las funciones de verificación que le asigna Kant. La instancia de la razón pública, ciertamente, cumple para Kant una función decisiva para la política. De hecho, en Sobre la Paz perpetua se establece como fórmula trascendental del derecho público que "son injustas todas las acciones que se refieren al derecho de otros hombres cuyos principios no soportan ser publicados" (Kant 1795: 381) y, en positivo, "todas las máximas que necesitan la publicidad (para no fracasar en sus propósitos) concuerdan con el derecho y la política a la vez" (Kant 1795: 386). Resulta sin duda solidario con estos principios toda la defensa del parlamentarismo que apela al carácter público de las discusiones como garantía de legitimidad para las leyes. Según los principios del parlamentarismo, en efecto, si la discusión legislativa se somete al escrutinio público, nadie tratará siquiera de hacer valer argumentos que resultasen intolerables desde el punto de vista de la validez general, es decir, nadie perderá el tiempo aduciendo razones de validez puramente privada pero que resulten inasumibles desde el punto de vista de la razón pública.

Contra este modo de justificar el parlamentarismo resultan sin duda del máximo interés los argumentos que apelan al efectivo secuestro del espacio público por parte de grandes intereses económicos y al carácter secreto con el que, de hecho, se toman la mayor parte de las decisiones relevantes en la vida política de los estados. Ninguna defensa decente del parlamentarismo puede sin más pasar por alto las objeciones de autores como Carl Schmitt o Lenin ${ }^{13}$.

13 En Sobre el parlamentarismo, Carl Schmitt sostiene que "la verdadera actividad no se desarrolla en los debates públicos del pleno, sino en comisiones (y ni siquiera necesariamente en comisiones parlamentarias), tomándose las decisiones importantes en reuniones secretas de los jefes de los grupos par- 
Sin embargo, desde el punto de vista de lo defendido aquí, lo central no es tanto el hecho de que el espacio público se halle efectivamente corrompido en las sociedades capitalistas desarrolladas. El objetivo aquí es simplemente analizar la consistencia interna de la concepción republicana de la política y aislar el elemento de "virtud cívica" que hay a su base. A este respecto, la pregunta que nos ocupa no es tanto si el "espacio público" está o no secuestrado (como de hecho lo está) sino si, en ausencia absoluta de todo principio moral, el escrutinio público podría proporcionar alguna garantía de la validez general de las leyes o si, por el contrario, el proyecto mismo de una comunidad jurídica organizada según principios republicanos exige siempre suponer una cierta moralidad cívica a su base. Y, en efecto, allí donde nadie estuviese dispuesto a ir un solo paso más allá de sus posiciones puramente privadas, allí donde no cupiese siquiera pensar la posibilidad de un punto de vista de validez general como algo distinto de las diferentes voluntades particulares (y, por supuesto, del mero agregado de todas ellas), allí donde no cupiese pensar la idea de una razón pública como algo distinto del simple conglomerado de razones privadas, allí simplemente carecería de sentido la posibilidad misma de la "discusión ciudadana" y no cabría más que negociar para acoplar entre sí, del modo más ventajoso posible para los beneficiarios, los intereses particulares de la mayoría (o quizá de los más fuertes). Bien es verdad que (al menos desde la Primera Guerra Mundial) nos hemos acostumbrado a llamar Parlamento a un sitio donde sólo se negocia. Sin embargo, se debe señalar que, en esas condiciones, no hay de iure ninguna posibilidad de desarrollar legislativamente un sistema propiamente de derecho en vez de la mera codificación de las costumbres mayoritarias o los intereses del más fuerte.

\section{La comunidad como presupuesto necesario}

Nada de lo planteado hasta aquí cobra sentido si no se presupone una cierta comunidad a la base. Ciertamente, el planteamiento de Kant no remite a ninguna comunidad sustancial ni exige una homogeneidad del cuerpo político. Para dotar de sentido a todo lo anterior, el proyecto republicano no reclama la existencia de lazos de sangre o vínculos culturales capaces de unir entre sí a los distintos miembros de un cuerpo político ${ }^{14}$. Ahora bien, en el planteamiento de Kant tampoco el "sentido

lamentarios o, incluso, en comisiones no parlamentarias" Schmitt (1923), p. 25. "Las cada vez más pequeñas comisiones de partidos o coaliciones de partidos deciden a puerta cerrada, y lo que deciden los representantes de los intereses del gran capital, en el comité más limitado, es, quizá, aún más importante para la vida cotidiana y el destino de millones de personas que las decisiones políticas" Schmitt (1923), p. 25. Por su parte, en El Estado y la revolución, Lenin sostiene que "la verdadera labor "de Estado" se hace entre bastidores y la ejecutan los ministerios, las oficinas, los Estados Mayores. En los parlamentos no se hace más que charlar, con la finalidad especial de embaucar al "vulgo"” Lenin (1917), p. 89.

14 A este respecto, José Luis Villacañas nos recuerda que Kant está tan lejos del concepto de comuni- 
común lógico" es suficiente para la constitución de una comunidad política. En efecto, eso que compartimos los humanos, por ejemplo, al hacer geometría es, sin duda, un modo de ocupar "en el lugar de cualquier otro" basado en conceptos y principios racionales. Sobre la base de ese "sentido común lógico" es posible, quizá, organizar una comunidad científica, pero en ningún caso es suficiente para organizar, a partir exclusivamente de él, una comunidad política. Por el contrario, la posibilidad misma de una comunidad política supone la existencia de cierto sustrato común constituido a la escala de la sensibilidad o del gusto, digamos, un "sentido común estético". En efecto, todo el planteamiento de Kant sí exige al menos suponer la posibilidad misma de algún modo de sentir común sin el cual no habría forma humana de colocarse, a la escala de la sensibilidad, en el "lugar de cualquier otro" (Kant 1790: 294). En efecto, hace falta presuponer cierto sustrato común para hacer inteligible esta máxima del Juicio, que exige ampliar o ensanchar el propio punto de vista para no restringirlo a condiciones meramente privadas y subjetivas sino, por el contrario, asumir un punto de vista universal, lo cual sólo se puede lograr poniéndose en el lugar de los demás ${ }^{15}$. La mera posibilidad de "ponerse en el lugar de otro" presupone un sensus communis, es decir: la idea de un sentido común a todos, que permita al Juicio tener en cuenta (a priori) el modo de representación de los demás para atenerse a la razón total humana ${ }^{16}$.

Debe tenerse en cuenta que al hablar de sensus communis, Kant no presupone la existencia efectiva de un modo de sentir común a la humanidad y, en esa medida, la existencia de una comunidad real. Para empezar, lo que se postula con la uni-

dad sustancial como de la reacción comunitarista al liberalismo de Rawls, Dworkin o Ackermann. "Cuando Kant habla del gemein Wesen, lo traduce, cuando lo hace, por la noción de res publica. Cuando prefiere dar la base social de esta formación jurídico-política, habla de bürgerlicher Gesellschatf. Por tanto, el sentido de Kant es organizar una res publica sobre la sociedad civil que ha caracterizado de forma liberal. La sociedad civil se basa en un general antagonismo y supone la voluntad privada de cada uno. La res publica se funda en una idea racional de contrato originario, como regla práctica necesaria de la legislación; y en un ideal del reino de los fines como arquetipo o res publica noumenon". Villacañas (2009), pp. 91-92.

15 Debe tenerse en cuenta aquí que esta exigencia de "ampliar" o "ensanchar" el Juicio no remite tanto a una cuestión relativa a la razón teórica como a la razón práctica. En efecto, esta "ampliación" o "ensanchamiento" no se refiere a la agudeza de la inteligencia ni a la amplitud o profundidad de los conocimientos sino, simplemente, al compromiso y la disposición a razonar saliendo de la cápsula de los intereses privados. "Aquí no se trata de la facultad de conocimiento sino del modo de pensar, para hacer de éste un uso conforme a fin; por muy pequeños que sean la extensión y el grado adonde alcance el dote natural del hombre, muestra, sin embargo, un hombre amplio en el modo de pensar, cuando puede apartarse de las condiciones privadas subjetivas del juicio, dentro de las cuales tantos otros están como encerrados, y reflexiona sobre su propio juicio desde un punto de vista universal (que no puede determinar más que poniéndose en el punto de vista de los demás)". Kant (1790), p. 294.

16 Como sostiene José Luis Villacañas, "la crítica aspira a la configuración de un sentido común, a la configuración de un ser sensible común". Villacañas (2009), p. 101. En efecto, "sin esta formación de un sentido común, la crítica genera crisis, no orden humano (...). Kant ha partido de la autonomía, pero todo en él apunta a lo común (...). Podemos decir que la crítica no es liberal ni comunitaria. La crítica es republicana" Villacañas (2009), pp. 101-102. 
versalidad de cualquier juicio de gusto no es tanto que todo el mundo estará de acuerdo con ese gusto como que todo el mundo debería estarlo (Kant 1790: 239). El modo de sentir común que se presupone en efecto al enunciar juicios de gusto no implica tanto una realidad como una tarea. Esta "comunidad" del sentir no es planteada por Kant como un principio constitutivo de la posibilidad de la experiencia sino como un principio regulativo que marca algo que hay que producir; no se trata de algo que esté dado como facultad originaria (común de hecho a todos los hombres) sino como exigencia de la razón. La necesidad de una comunidad que concuerde al menos en el modo de sentir, condición sin la cual resultaría imposible ponerse en "el lugar de cualquier otro", es algo que se presenta ante todo como un deber (Kant 1790: 294 y 296).

Ahora bien, la posibilidad y la disposición, supuesta al menos de iure, a pensar desde el "lugar de cualquier otro" es, en definitiva, lo que marca la diferencia entre razonar encapsulado en los intereses privados e intentar ubicarse en un punto de vista de validez general. Es decir, es lo que marca la diferencia entre deliberar y negociar, entre un Parlamento y un mercado o entre un ciudadano y un comerciante. En efecto, a partir únicamente de regulaciones externas, mediante la astucia de determinados resortes y dispositivos, es sin duda posible lograr algún modo de compatibilidad de los distintos intereses privados entre sí. Pero la política no puede ser sin más un mecanismo de agregación infinitesimal de deseos y voluntades particulares. La política no puede limitar sus pretensiones al intento de acoplar, como hace el mercado, unos intereses privados con otros. Y ese elemento que distingue un mercado de un parlamento (y que remite en definitiva a la posibilidad, al menos de iure, de razonar y legislar desde el "lugar de cualquier otro") es algo que no se puede de ningún modo imponer coactivamente ${ }^{17}$.

17 A este respecto en el que resulta ineludible cierta disposición que, sin embargo, no se puede imponer de ningún modo coactivamente, es imposible exagerar la importancia del sistema educativo.

Cualquier padre o madre sabe que la principal tarea de la educación es lograr que el niño asuma que no es el centro del universo sino "uno cualquiera". En este sentido, quizá la pregunta más repetida en cualquier espacio de convivencia infantil sea "¿a ti te gustaría que te hicieran lo que le acabas de hacer a X o Y?".

Pero, para lograr este objetivo, resulta irrenunciable un sistema de educación generalizado y exclusivamente público. En caso contrario, es imposible garantizar que los niños no son educados como "un blanco cualquiera" ( $\sin$ nada en común, por ejemplo, con "negros, indios y moros"), "un católico cualquiera" (sin nada en común, por ejemplo, con los "ateos que quieren destruir la Familia") o como "un emprendedor cualquiera" ( $\sin$ nada en común con las "clases subalternas"). En efecto, en caso de dejar la educación en manos exclusivamente de los padres o de los centros elegidos a la carta por ellos, no hay ninguna garantía de que se vaya a educar a los niños para que se comporten como un "ciudadano cualquiera", es decir, que se pongan en el "lugar de cualquier otro" con un alcance verdaderamente universal.

Ahora bien, es imprescindible no perder de vista que esta disposición a razonar desde el lugar de cualquier otro se logra con más eficacia a través del conocimiento teórico que del adoctrinamiento moral. En efecto, la vía más segura para colocarse en un punto de vista de validez general es participar en las 
Ahora bien, si imaginamos una supresión radical de toda posibilidad (siquiera de iure) de pensar desde el lugar de cualquier otro, es decir, si suponemos una radical ausencia de todo lugar común (siquiera como deber), entonces el resultado no puede ser sino una muchedumbre de voluntades particulares permanentemente dispuestas a engañarse unas a otras (si lo considerasen conveniente para su propio interés privado). En estas condiciones, en contra de lo que supone la ideología liberal, no hay proyecto social que resulte viable. Si no se parte más que de la base exclusiva del cálculo utilitario y el interés privado, si no se introduce en absoluto más principio que el de maximización del interés individual y, por lo tanto, si no se supone más lazo, vinculación o unión entre los hombres que el del intento permanente de aprovecharse unos de otros, lo más probable es que no fuera posible siquiera el lenguaje y, en cualquier caso, resultaría del todo imposible fundar ninguna sociedad 18 .

En contra de lo que plantea el liberalismo económico (y una parte de las teorías de la racionalidad práctica que le acompañan), no hay proyecto de sociedad que pueda resultar viable en esas condiciones. En efecto, de entre las distintas utopías que ha intentado ensayar la humanidad a lo largo de su historia, la más descabellada de todas ha sido la intentada llevar a cabo por el liberalismo económico: la uto-

conquistas de la razón humana en el terreno de las distintas ciencias. Si hay algún sitio donde no se puede estar de ningún modo más que en "el lugar de cualquier otro", es, precisamente, en una clase de matemáticas.

[En el proceso de evaluación ciega de este artículo, uno de los evaluadores hizo al respecto una observación tan acertada que no nos resistimos a citar literalmente: "Pienso que el niño se debe sentir de igual modo "uno cualquiera" y a la vez el centro del mundo, como corresponde a un ser libre y amado. El amor de los padres singulariza, y le hacer ver al niño que él es también único, significativo, real como individuo. Sin uno de esos dos sentimientos-pensamientos el niño quedaría o vacío (sin peso específico de ser) o ciego (para orientarse éticamente en la comunidad), por utilizar el símil kantiano". Ciertamente, es difícil imaginar una utopía más inverosímil y, sobre todo, más indeseable que un mundo en el que los padres tratasen a sus propios hijos como si fueran cualquier otro (es decir, como a niños cualquiera) en vez de tratar a sus hijos como lo haría cualquier padre (es decir, como el "centro del mundo"). Pongamos un ejemplo: un mundo en el que los tribunales de justicia no hicieran lo posible por intentar ser imparciales sería un mundo injusto. Por eso es razonable que un juez tenga el deber de abstenerse y pueda ser recusado en caso de corresponderle juzgar respecto a asuntos que conciernen a sus propios hijos. Sin embargo, un mundo en el que ya no fuese necesaria la abstención ni la recusación en esos casos porque, de todos modos, pudiera estar garantizada la "imparcialidad" (es decir, pudiera estar garantizado que los padres tratarían a sus hijos como a "cualquier otro" ante el tribunal), ese quizá no sería un mundo injusto, pero sí sería un mundo insoportable.]

18 Tiene sin duda razón Santiago Alba Rico cuando sostiene que hay ciertas convicciones que preceden al contrato social mismo, sin las cuales no podría haber ningún tipo de contrato social y que, en definitiva, remiten al supuesto de que no todos los hombres ni en todas las ocasiones actuamos por interés. Sin ciertas convicciones de este tipo, como sostiene Alba Rico, no nos atreveríamos siquiera a preguntar la hora o la ubicación de una calle a un desconocido. "Por muy mala que sea la opinión que tengamos de nosotros mismos, por mucho que desconfiemos en la naturaleza del ser humano, todos los días, a todas horas, estamos confiando alegremente nuestra vida, nuestras propiedades, nuestra seguridad, nuestros placeres, a intervenciones ajenas que el cálculo o el interés, de alguna forma, inmovilizarian". Alba Rico (2007), p. 238. 
pía de una sociedad de mercado. Ciertamente, el intento de sustituir todas las instituciones sociales por el mercado (y la pretensión de que esto no sólo podía sino que debía hacerse y, además, debía hacerse con un alcance universal) es un proyecto de una radicalidad sin precedentes que estaba condenado al fracaso desde su primera formulación. En efecto, de entre los diversos experimentos sociales imprudentes que se han ensayado jamás, quizá el más estrafalario haya sido el de confiar toda la organización social a un principio de maximización del propio interés que no sólo encuentra dificultades insalvables para fundamentar la validez y la legitimidad de las leyes sino que es incluso incapaz de incorporar hechos tan elementales como que, por lo general, los padres cuiden de sus hijos con relativa independencia de cálculos egoístas (Alegre Zahonero 2006: 105).

Como es lógico, allí donde se ha tratado de ensayar, el experimento no se ha logrado imponer simplemente a fuerza de predicar la libertad y la no injerencia de las instituciones en la actividad de los individuos sino, por el contrario, mediante una intervención política (y militar) sin precedentes destinada a convertir la tierra y el trabajo (o, en terminología marxista, la "fuerza de trabajo") en mercancías y, con ello, a destruir todos los posibles vínculos sociales y las instituciones culturales de cualquier sociedad orgánica para sustituirlos por relaciones mercantiles. En efecto, conviene recordar con Polanyi que "es como si en un momento dado se decidiese en la práctica que las organizaciones no contractuales fundadas en el parentesco, la vecindad, el oficio o las creencias, debían ser liquidadas, puesto que exigían la sumisión del individuo y limitaban por tanto su libertad. Presentar este principio como una medida de no injerencia, como sostenían comúnmente los partidarios de la economía liberal, equivalía a expresar pura y llanamente un prejuicio enraizado en un tipo muy particular de injerencia, a saber, la que destruye las relaciones no contractuales entre individuos y les impide organizarse espontáneamente". Según trata de demostrar Polanyi, no hay sociedad que pueda sobrevivir edificada exclusivamente sobre los cimientos del mercado. El poder "disolvente" de la acción del mercado sobre cualquier vínculo comunitario impone la disolución completa de toda posible sociedad. De hecho, lo que Polanyi nos recuerda es que las sociedades que han sobrevivido lo han hecho precisamente a base de defenderse del mercado y no de profundizar en él. El "cemento" con el que edificar una sociedad y dotar de consistencia orgánica a sus instituciones culturales no es ni puede ser de ningún modo el intento permanente y generalizado de aprovecharse unos de otros.

Ahora bien, ese cemento con el que construir sociedad puede buscarse, sin duda, en cosas del tipo relaciones de parentesco y lazos comunitarios, capaces de tejer ciertamente una malla que dote de consistencia a la sociedad, pero a costa de que esa vinculación (ese sistema, digamos, de solidaridad recíproca) constituya una comunidad y excluya de ella, al mismo tiempo, al resto de la Humanidad. Sin embargo, si no se quiere caer en posiciones comunitaristas y localistas ni renunciar al ideal de una República cosmopolita, resulta necesario recurrir a algún tipo de sen- 
timiento que, por un lado, nos vincule efectivamente unos a otros, pero nos vincule ante todo y mayormente como miembros por igual de la Humanidad.

Esa posibilidad de una "comunidad en el grado cero de lo social" constituye, pues, una condición en ausencia de la cual sería imposible ninguna sociedad verdaderamente civil y cosmopolita. La Fraternidad en la tradición republicana o el Humanismo en los proyectos emancipatorios de corte cristiano representan sin duda modos de referirse a esa idea previa de comunidad sin la cual ninguna comunidad concreta podría ser justamente humana. En efecto, lo que se busca precisamente cuando se persigue la Fraternidad o el Humanismo es algún principio que resulte, por un lado, capaz de dotar de consistencia a una sociedad (es decir, algún principio que resulte suficientemente potente para establecer vínculos sólidos entre unos individuos y otros) pero que sea por otro lado, al mismo tiempo, un principio enteramente universal y vacio (es decir, que vincule a unos con otros como miembros de la Humanidad, sin basarse en ningún contenido o patrón de comportamiento concreto que pretenda imponerse a todos para reconocerlos y aceptarlos como miembros de esa sociedad).

Entre el vacío inhumano del mercado (que no introduce más vínculo, ni unión, ni relación entre las personas que el enfrentamiento de todos con todos en la búsqueda exclusiva del interés privado de cada uno) y la densidad demasiado humana de las comunidades cerradas, opacas y excluyentes (que logran ser compactas sólo a costa de imponer como obligatorios determinados contenidos y pautas de comportamiento), no podemos sino depositar en esos sentimientos universales de Humanidad o Fraternidad (que, siendo sentimientos, tienen sin embargo vocación necesaria de universalidad) la esperanza de conseguir fraguar, precisamente, sociedades de ciudadanos.

\section{Referencias bibliográficas}

Alba Rico, S. (2007): Capitalismo y Nihilismo. Dialéctica del hambre y la mirada. Madrid, Akal.

Alegre Zahonero, L. (2006): "El conflicto de las racionalidades", Nexo, nº3, pp. 93-108.

DOMĖNECH, A. (1989): De la ética a la política. De la razón erótica a la razón inerte. Barcelona, Crítica.

Kant, I. (1788): Kritik der praktischen Vernunft, Akademie-Ausgabe, Bd. V, Berlín (traducción: E. Miñana y Villagrasa y Manuel García Morente (1998): Crítica de la Razón práctica, Salamanca, Ediciones Sígueme)

Kant, I. (1790): Kritik der Urteilskraft Akademie-Ausgabe, Bd. V, Berlín (traducción: Manuel García Morente (1997): Crítica del Juicio, Madrid, Espasa Calpe) Kant, I. (1793): Die Religion innerhalb der Grenzen der bloßen Vernunft, 
Akademie-Ausgabe, Bd. VI, Berlín (traducción: Felipe Martínez Marzoa (1995), La religión dentro de los límites de la mera Razón, Madrid, Alianza)

Kant, I. (1795): Zum ewigen Frieden, Akademie-Ausgabe, Bd. VIII, Berlín (traducción: Antonio Truyol y Serra (1998): Sobre la paz perpetua, Madrid, Tecnos)

Kant, I. (1797): Die Metaphysik der Sitten, Akademie-Ausgabe, Bd. VI, Berlín (traducción: Adela Cortina Orts y Jesús Conill Sancho (2002): Metafisica de las costumbres, Madrid, Tecnos)

KerstinG, W. (2009): "Kants Gemeinschaftsphilosophie vom commercium der Substanzen bis zum ethischen Staat", Logos. Anales del Seminario de Metafisica, $\mathrm{n}^{\circ}$ 42, pp. 73-88.

KerVÉgan, J.F. (2009): "Le droit cosmopolitique comme droit", Logos. Anales del Seminario de Metafisica, $\mathrm{n}^{\circ}$ 42, pp. 9-24.

LENIN, V.I. (1917): El Estado y la revolución. Madrid, Alianza.

Martínez MarzoA, F. (2008): El concepto de lo civil. Santiago de Chile, Metales Pesados.

Schmitt, C. (1923): Sobre el parlamentarismo. Madrid, Tecnos.

Villacañas, J.L. (2009): "Lo común en Kant", Logos. Anales del Seminario de Metafisica, n 42, pp. 89-104.

Luis Alegre Zahonero

Dpto. Teoría del Conocimiento,

Estética e Historia del Pensamiento

Facultad de Filosofía

luis.alegrezahonero@gmail.com

Carlos Fernández Liria

Dpto. Filosofía Teorética

Facultad de Filosofía

ferliria@gmail.com 